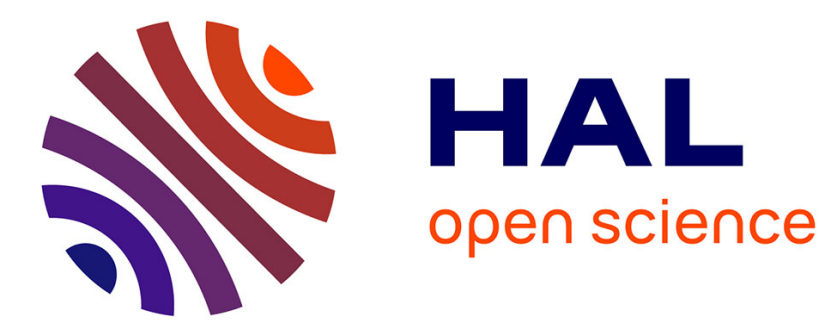

\title{
FMEA and consideration of real work situations for safer design of production systems
}

Aurélien Lux, Johann Mawo de Bikond, Alain Etienne, Edwige

Quillerou-Grivot

\section{- To cite this version:}

Aurélien Lux, Johann Mawo de Bikond, Alain Etienne, Edwige Quillerou-Grivot. FMEA and consideration of real work situations for safer design of production systems. International Journal of Occupational Safety and Ergonomics, 2016, 22 (4), pp.557-564. 10.1080/10803548.2016.1180856 . hal-01345324

\section{HAL Id: hal-01345324 \\ https://hal.science/hal-01345324}

Submitted on 27 Jan 2017

HAL is a multi-disciplinary open access archive for the deposit and dissemination of scientific research documents, whether they are published or not. The documents may come from teaching and research institutions in France or abroad, or from public or private research centers.
L'archive ouverte pluridisciplinaire HAL, est destinée au dépôt et à la diffusion de documents scientifiques de niveau recherche, publiés ou non, émanant des établissements d'enseignement et de recherche français ou étrangers, des laboratoires publics ou privés. 


\section{FMEA and consideration of real work situations for safer design of production systems}

Aurélien LUX(1), Johann MAWO DE BIKOND(2), Alain ETIENNE(2), Edwige QUILLEROU-GRIVOT(1)

Johan.MAWO-DE-BIKOND@ensam.eu

alain.etienne@ensam.eu

edwige.quillerou@inrs.fr

(1) Institut National de Recherche et de Sécurité (INRS), France

${ }^{(2)}$ Ecole Nationale Supérieure des Arts et Métiers (ENSAM), France

Short form of the title: FMEA, work situations and safe design

Keywords: design, ergonomics, FMEA, work situations, margins for manoeuvre

Correspondence to:

Aurélien LUX

aurelien.lux@inrs.fr

INRS (Institut National de Recherche et de Sécurité)

1 Rue du Morvan 54519 Vandoeuvre-les-Nancy

France

\section{Abstract}

Production equipment designers must ensure the health and safety of future users; in this regard, they augment requirements for standardising and controlling operator work. This contrasts with the ergonomic view of the activity, which recommends leaving operators 
leeway (margins for manoeuvre) in performing their task, while safeguarding their health. Following a brief analysis of design practices in the car industry, we detail how the Failure Modes and Effects Analysis (FMEA) approach is implemented in this sector. We then suggest an adaptation that enables designers to consider real work situations. This new protocol, namely work situation FMEA, allows experience feedback to be used to defend the health standpoint during designer project reviews, which usually only address quality and performance issues. We subsequently illustrate the advantage of this approach using two examples of work situations at car parts manufacturers: the first from the literature and the second from an in-company industrial project we followed.

\section{PROBLEM}

Work equipment design is a prime prevention area and its importance is fully acknowledged in the occupational health and safety field: the integrated prevention strategy is currently shared by all European countries [1]. Its purpose is to achieve a minimum level of health and safety risk for users of future production systems. Hence, there has been extensive scientific research aimed at assisting designers in their risk assessment and reduction approach [2, 3, 4]. Designers can also resort to standards, which do not represent a regulatory duty, but do reflect current knowledge and technology. In the prevention of musculoskeletal disorders (MSDs), a major occupational health challenge [5], ergonomic standards are therefore of assistance in assessing operator stresses, whether they be related to their physical [6] or mental [7] workload. These normative benchmarks are mainly based on a biomechanical approach to ergonomics, sometimes termed task ergonomics [8]. This approach relates to a model of the standard human being and leaves little leeway for considering variability, which is nevertheless inherent to every work system or situation ${ }^{1}$. This variability can be technical (machine failure), organisational (no colleague, response to production urgency), or human (variability amongst and within individuals).

Studying real work situations and their variabilities lies at the very heart of analyses performed using activity-centred ergonomics, a francophone approach, which considers work as close as possible to operator reality. Many studies implement activity ergonomics at design stage $[9,10,11,12,13,14]$. Emphasis is placed on the fact that there is invariably a major difference between what the designers have imagined and stipulated (the task) and what will ultimately be performed by the operators (the activity); one line of occupational risk 
prevention then involves leaving the operators sufficient leeway (margins for manoeuvre) to be able to adjust their way of working to the situation, to what appears to them most suitable or least stressful, to what is possible or impossible, etc. $[15,16]$. This leeway is reflected, for example, by the possibility for the operator to vary his/her gestural activity [17], to adjust his/her rhythm of work or to work in a pair based on a suitable workstation spatial configuration [18]. Margins for manoeuvre of this type thus enable operators to reach an acceptable compromise between performance and personal commitment, while safeguarding health.

It is therefore up to the designers to create these margins for manoeuvre [19] or at least conserve those that exist already to ensure that systems are adaptable to the work activity and not just to an average nominal situation. However, these objectives remain far removed from existing practices of designers. They have no formal means or tools for considering this notion of margins for manoeuvre and, more generally, this approaching of work situations [20]. On the contrary, designers seek to limit as much as possible all forms of variability and to standardise work situations for reasons of cost, quality and production time. This is especially true in relation to deployment of lean manufacturing-type rationalisation approaches, in which systematic elimination of so-called no added value actions (holding, displacements, buffer stocks, etc.) tends to reduce operator margins for manoeuvre [21, 22]. In this context, this paper introduces an approach aimed at helping engineers and technicians to integrate this need to consider work situation variability into their design projects and to conserve operator margins for manoeuvre.

The principle retained is to base design work as much as possible on the methodological tools known to designers to facilitate subsequent adoption of the approach.

\section{STATE OF THE ART}

\subsection{Design practices}

Prior to conducting the study described in this paper, an exploratory survey was held at 10 French car industry subcontractors. Discussions with manufacturers in particular provided confirmation of the main contextual problems experienced in the car sector design activity: budget is the greatest constraint in this competitive environment and represents a limit to considering operator health and safety in the design process. For example, some companies admitted to overlooking workstation ergonomics during project development for cost reasons. This observation corroborates the results of a 2012 survey of Swedish designers: half the engineers questioned observed that regulatory constraints alone were not enough to ensure deployment of ergonomic solutions, if they were expensive [23]. Lack of time is also a 
problem for designers, who sometimes have to leave workstation and work standard finalisation in the hands of production sites. Hence, in the face of client diversity, designers have to work with multiple order givers embodying different practices and cultures: each implementing its own reference frame (design, quality, purchasing, logistics, etc.) involving specific operating methods, formalisms and constraints.

This exploratory survey also provided an up-to-date view of procedures and methodological tools used to design new production equipment. In particular, it showed that the Failure Modes and Effects Analysis (FMEA) procedure was implemented in all 10 of the companies surveyed. This approach is effectively often imposed by their clients (car and car part manufacturers). By following a design project at one of this companies, we were able to confirm that regular FMEA meetings attended by design, production planning and methods, quality, management and production itself were held throughout the design process and that this analysis evolved in line with the decisions and directions adopted for the project.

\subsection{Use of FMEA}

FMEA is a procedure used in design to analyse a priori the risks of failure of the designed product or its manufacturing process, which could have unwanted effects on its quality. Initially developed by the American army [24], FMEA has gradually been adapted to other civil sectors, firstly in the aerospace industry and subsequently in the car industry, in which it has imposed itself long term [25]. Several types of FMEA (Design, Process, System, Logistics, etc.) are used depending on the system, to which the analysis is applied. This paper only refers to Process FMEA (P-FMEA) since our problem primarily concerns the design of production equipment. P-FMEA has been methodically applied [26] to the product manufacturing process, which it has been necessary to break down into elementary production stages. For each of these stages, the P-FMEA starts with a survey of potential or already proven process failures. The effects, causes and means of detecting these failures are then sought and consolidated in a summary table (see Table 1). The failures are then prioritised by applying a criticality index RPN (Risk Priority Number) calculated from three scores between 1 and 10 . These scores relate to the severity of the failure effect (S), its probability of occurrence $(O)$ and the probability of detecting the fault (D). Corrective action is required beyond a certain RPN threshold defined by the company. A manager and expected deadline are then assigned to this action. A new provisional rating (S', O', D') then allows definition of the criticality RPN' of the corrected situation and confirm whether it effectively corresponds to the expected level of reliability. 
Various studies have already attempted to improve the FMEA procedure, in particular by pointing out the limits of the failure rating and prioritisation system [27] or by trying to enrich it with new parameters: e.g. by considering costs [28] or factors related to a lean system [29]. Proposals also exist for using formalisms close to FMEA in the risk prevention field: some authors thus take into account the cost of risks caused by an unergonomic design [30]. Village et al. propose a Human Factors-FMEA for analysing each failure causing risks to quality and operator health and safety [31]. The Safety-FMEA [32] also represents a procedure for analysing the risk to user safety of a work equipment item. This takes into account the probability of a hazardous situation arising, the operator exposure time and his/her avoidance options, and the severity of potential injuries. This approach aimed at assisting designers in their a priori risk assessment process is nevertheless restricted to accident risks.

This theoretical view of FMEA and its spin-offs, as well as knowledge of its usage in the car industry provided confirmation of its readiness to support our research. The procedure is effectively multidisciplinary and iterative, and it can be applied right from the first stages of a new production line design process; this corresponds closely to the characteristics expected of an integrated occupational risk prevention approach [1,33].

It is important to remember that, unlike Berthe \& Vimeux [32], our aim is not to use P-FMEA for a priori risk assessment, but to contribute to it by taking special care to conserve operator margins for manoeuvre. The purpose of the P-FMEA development proposed in this paper is to widen the initial analysis area by integrating therein experience feedback data on real work situations and differences observed with respect to stipulated operating procedures.

For the developed approach to be used, it must consider the restricted context, to which the car industry designactivity is subjected (cf. 2.1). The approach must also curtail its impact on the design process by minimising any additional costs and times that it may generate. Furthermore, it must be flexible enough to adapt itself to different benchmarks imposed by multiple ordering parties.

\section{METHODOLOGY}

Theoretical research based on P-FMEA has prompted us to propose an adaptation thereof, which we call work situation-FMEA (WS-FMEA). The P-FMEA formalism has therefore been modified to offer designers the possibility of adding a health and safety dimension into their production equipment reliability and quality improvement process. 
We use an example from the literature to illustrate our proposed approach and construction of the related support. This support, which takes the form of a table, is the starting point enabling the project team to exchange around operator activity, which is rarely discussed at design stage.

We then apply WS-FMEA to a second example emanating from a case study we conducted at a car industry subcontracting company, which involved monitoring a production line modification project. The approach was then presented to, and discussed with, the project team at this company.

\section{RESULTS}

\subsection{WS-FMEA: Work Situation Failure Mode \& Effects Analysis}

Construction of the WS-FMEA procedure and the related table involved retaining the following columns and parameters:

- Process step. This first column is identical to that of P-FMEA and allows the analysis to be broken down station by station, operation by operation. This condition is essential. It is in fact the common starting point for both P-FMEA and WS-FMEA analyses, which can therefore be conducted in parallel, while remaining related.

- Real work situation. This second column allows experience feedback to be introduced by identifying work situations out of compliance with stipulated nominal conditions. This column therefore shows the variability in all its previously described forms: it is important that the users validate collectively the variability data reported in this column. Their relevance to working conditions will hence be legitimate. Different methods emanating from the ergonomic approach (observations, interviews, selfconfrontations, etc.) can be used in this connection [34];

- Causes/Effects, risks. In these 2 columns, we analyse in a participative way the reasons underlying the identified deviations and their potential effects on the work situation. Based on the literature [35, 36, 37], 3 criteria were therefore retained for qualifying them: performance, quality and working conditions. A cause or effect can therefore stem from one or more of these criteria;

- Severity/Probability/Criticality. In a conventional FMEA, standard rating charts are often used to assess failure criticality and prioritise the action plan. In the same way, severity and probability criteria were selected to characterise the risks identified in the WS-FMEA. This description does not include the method of calculating these criteria, thereby leaving it up to the FMEA teams to develop their own assessment scales; 
- Actions. Envisaged actions can be of three types:

- Validate: the existing situation is acceptable. Within a prevention perspective, this option is possible if the observed deviation represents an operator health and safety risk (Working conditions box checked in the Effects-Risks column);

- $\underline{\text { Reject: }}$ the existing situation is unacceptable and the nominal situation must be restored. Again, within a prevention perspective, this option will be impossible if the working conditions have caused the deviation (Working conditions box checked in the Causes column);

- Supervise: the situation is acceptable subject to improvement. For example, measures must be taken to ensure that the operation is safely performed.

To illustrate the proposal embraced by this new table, we base ourselves on a work situation example described in the literature within the scope of an ergonomic operation conducted at a car parts manufacturer. This study revealed, in particular, that production line work crews spend nearly a third of their time working outside the standard operating procedure [38]:

"...for example, one of them (production crew) builds up a stock of 6 work-in-progress parts in the middle of its line. The maximum authorised number (a standard) is 3 parts in progress. But the crew has learnt that, when a very specific maintenance fault occurs on one of the machines, its resolution time corresponds to de-stocking of 6 parts. Despite maintenance department interventions, this fault is recurrent, almost daily. Contravening the standard by doubling the work-in-progress stock avoids a break in the production flow".

To integrate this view of a real work situation, the WS-FMEA table was completed as follows:

\section{Table II}

The observed real work situation is characterised by line operation with a mid-line stock of 6 parts in progress instead of 3. This doubling of the stock can be taken into account in WSFMEA procedure because it is validated by all operators involved: "..., the work group agreed to deviate from the operating standard and to adopt strategies (stock doubling) capable of anticipating a work incident (machine failure)".

The Performance box in the Causes column is therefore checked since the operators deviate from the required standard to avoid a break in the line flow and guarantee production continuity. 
The Working conditions box is checked in the Effects-Risks column. The ergonomic analysis effectively indicates that this deviation from the operating standard represents a health risk for operators, who have to conceal it from their management: "in the case of doubling the 3 parts in progress required by the standard to 6 , the crew intentionally reduces this number to zero, during its work break, to leave the line visibly empty, thereby preventing management from having to issue reprimands". ... "Far from being fun, this game is not without danger. It confines the work crew's operating resources to darkness, at best reducing them to a trivialised form, at worst transforming them into a stigmatising burden".

The Quality box is also checked because of the potential risks of scratching the products under uncontrolled storage conditions.

With regard to the actions to be implemented and applying the proposed rules, it may therefore be decided to tolerate this operating practice with 6 work-in-progress parts subject to its supervision: for example, a suitable support could be installed to prevent the risk of degrading part quality. On the other hand, the project team could not reject the deviation and continue to impose a 3-part stock; this would amount to constraining the operators, obliging them to follow a theoretical standard and depriving them of the necessary margins for manoeuvre in confronting work system instability.

\subsection{Application of WS-FMEA in a manufacturing case}

Let us now consider the following real situation encountered during our case study at a car parts manufacturer: this involved analysing an assembly operation for a clip used to secure an electrical wiring harness on a plastic component. Table III shows a line of the P-FMEA that assesses the quality risks involved in this operation. This analysis extract is representative of a "conventional" P-FMEA procedure of the kind practised at this company.

\section{Table III}

If the clip is not installed (failure), the part may be noisy after assembly and usage on the vehicle (effect). The main identified cause of this failure is operator oversight. The only means of detection initially envisaged was visual inspection performed by the operator. After rating, the RPN of 75 proved critical (exceeding the threshold value of 36 specified by the company) and an action plan was implemented: a so-called hand-passing sensor, detecting the presence of the operator's hand in the clip supply bin, was duly added. If the status of this sensor does not change before the end of the production cycle, the part is blocked at the workstation and cannot be transferred to the following step. 
As this example shows and as is often the case, P-FMEA analyses are essentially technical: human factors are rarely involved and, when the operator is considered, it is as a potential cause of failure (the cause is then referred to by expressions such as "operator oversight", "operator mistake", "operating procedure not respected", etc.). As noted when attending FMEA meetings, there is usually no in-depth analysis to determine the reasons for these "mistakes" or deviations from the standard laid down.

Moreover, action plans often result in reinforcement of design "barriers" to curtail work variability. In the above example and according the Hollnagel's proposed classification [39], the initial, so called immaterial, barrier (operating procedure requiring simple visual inspection) was strengthened by installing a second barrier, the hand passing sensor, which is functional this time.

Table IV illustrates the WS-FMEA procedure for this clip installation operation: the designers were planning to reproduce the solution implemented on a similar line (hand passing sensor), but the production manager mentioned that the operators stored the clips in their pockets, despite this device. Workstation observation effectively confirmed that most operators bypassed the procedure and the installed hand passing sensor. This deviation from the standard allowed the operators to anticipate clip fitting at the previous workstation and thereby ensure production, while giving themselves margins for manoeuvre. The causes referred to were related to performance (time saving) and working conditions (comfort). The main potential effect of this deviation involves product quality. The risk of forgetting to install the clip since the detection system is (already) systematically bypassed. In applying the proposed action, the designers simply validate an existing situation: this option would effectively come down to reinforcing the barriers (procedures, sensors, etc.) to constrain the operators, obliging them to follow the specified operating procedure, by curtailing their margins for manoeuvre. They can only validate or else control the existing situation: a possible solution possible would then be to control this practice, without prohibiting it, and to ensure clip presence by other means (e.g. using a clip detector installed at the next workstation). Performance and working conditions would thereby be improved, while minimising the quality risk.

\section{Table IV}

This action was then presented to, and discussed with, the manufacturing partner, who confirmed its advantage: Technicians and engineers are in fact fully conscious that they deal with problems by developing technical solutions, but this new approach enables them to analyse the impact of their decisions on the real work of operators and to consider human factors in their design. 


\section{DISCUSSION AND CONCLUSION}

The investigative survey of designers at car parts manufacturers and this research have revealed the importance of extending the P-FMEA procedure beyond the usually adopted unique standpoints of quality and performance. In this connection, we have proposed the WS-FMEA model, which is based on formalism close to that already implemented by designers. This approach therefore integrates naturally into the design process, mobilising no additional resources or time since the main stakeholders are already in place within the P-FMEA framework.

The two examples processed using this approach highlight the significance of conducting a cause and effect analysis, based on the real work situation, for each step considered in a conventional P-FMEA. The design team can then assess the impact of its decisions and of the different production practices observed on the basis of three criteria: performance, quality and working conditions. Designers and prevention specialists can then start discussions around factors involving the variability of real work situations. This procedure thereby contributes to conserving or providing margins for manoeuvre essential to operator health and safety. It falls within an integrated prevention framework and reinforces the idea that only a holistic approach to the man-at-work model will achieve an optimum organisational performance level [40].

Discussions with the manufacturers we met also involved the formalism of the tables used. Two options are in fact feasible. either separating the two tables or merging them by creating two lines for each process stage (one for quality aspects, the other for work situation aspects). The second option offers the advantage of having only one support, but it nevertheless requires care at the failure mode prioritisation stage since the failure modes are different in the two approaches. Moreover, the P-FMEA is often a contract document required by the client in a specific format for its own quality reference frame, which requires part of the data contained in it. Using a second table allows us to overcome these two constraints, although the option retained depends ultimately on the company and its practices.

The significance of the FMEA approach depends on availability of data allowing more accurate failure characterisation and action plan prioritisation; both production and customer experience feedback are important for this: defect frequency and detection capability, failures, warranty-based returns, etc. This is all the more true for the WS-FMEA, which 
highlights the differences between specified standards (instructions) and work reality. It is therefore important to have relevant experience feedback enabling us to envisage not only work situations, but also variability and malfunctions. Availability of a process similar to that being designed is therefore helpful so that problems raised can be transposed and applied to the future project. The more innovative the design, the more difficult it is to provide factual data for analysing potential work situation variability. While the retained formalism therefore enables one to work on innovative projects in terms of technology and organisation, the approach is more easily applicable to projects involving the re-design, modification or adaptation of already known processes.

Another limitation arises, when one questions the willingness and real capacity of designers to integrate operator working conditions into their design process. Are they indeed capable of managing new constraints associated, on the one hand, with building up usable experience feedback and, on the other hand, with managing the actions required to take employee health into account? All the more so since consideration of work situation variability equates to partially calling into question their way of designing. However, every operator comment and expectation concerning working conditions cannot all be considered by designers: Operator involvement in design processes often prompts multiple non-constructive criticisms and contradictory demands, which ultimately tends to increase deadlines [20]. Hence, the existing activity needs to be analysed in detail in order to identify the important elements of the experience feedback. Ergonomic analysis of work situations similar to that being designed can list individual, industrial or organisational variabilities in association with knowledge of the man-at-work model. Research therefore continues on the interrelationship between production activity and design, focusing on the one hand on methods of acquiring experience feedback [34] and, on the other hand, on knowledge of the design discipline. These two lines of thinking will ultimately enable identification of levers for action favourable to consideration of occupational risk prevention requirements right from design stage. 


\section{$\underline{\text { References }}$}

1. Directive 2006/42/EC of the European Parliament and of the Council of 22 June 1998 on the approximation of the laws of the Member States relating to machinery. OJ. 2006;L157:24-86.

2. Neuman P. Production ergonomics, identifying and managing risk in the design of high performance work systems [doctoral dissertation] Lund: Lund University; 2004.

3. Hale A, Kirwan B, Kjellén U. Safe by design: where are we now? Safety Science. 2007; 45: 305-327.

4. Ghemraoui R, Mathieu L, Tricot N. Design method for systematic safety integration. CIRP Annals - Manufacturing Technology. 2009; 58(1): 161-164.

5. Eurofound. Fifth European Working Conditions Survey, Publications Office of the European Union; Luxembourg; 2012. Retrieved January 6, 2014, from: http://www.eurofound.europa.eu/pubdocs/2011/82/en/1/EF1182EN.pdf

6. European Committee for Standardization (CEN). Safety of machinery - human physical performance - part 3: recommended force limits for machinery operation (Standard No. EN 1005-3:2002+A1:2008). Brussels: CEN; 2008.

7. European Committee for Standardization (CEN). Ergonomic principles related to mental workload - part 2: design principles (Standard No. EN ISO 10075-2:2000). Brussels: CEN; 2000.

8. Hubault F, Bourgeois F. Disputes sur l'ergonomie de la tâche et de l'activité, ou la finalité de l'ergonomie en question [Disputes involving task and activity ergonomics or purpose of ergonomics concerned]. Activités. 2004; 1(1): 34-53.

9. Moraes ASP, Arezes PM, Vasconcelos R. From ergonomics to design specifications: contributions to the design of a processing machine in a tire company. Work. 2012; 41 : 552-559.

10. Sagot JC, Gouin V, Gomes S. Ergonomics in product design: safety factor. Safety Science. 2003; 41: 137-154.

11. Theureau J, Pinsky L. Paradoxe de l'ergonomie de conception et logiciel informatique [Paradox of ergonomics in design and computer software]. Revue des conditions de travail. 1947; 9: 25-31.

12. Daniellou F. Les modalités d'une ergonomie de conception, son introduction dans la conduite des projets industriels [Rules for design-based ergonomics and its introduction into industrial project management] (Note documentaire ND1647-129-87). Québec: INRS; 1987.

13. Maline J. Simuler le travail [Simulating work]. Lyons: Editions de l'ANACT; 1994. 
14. Garrigou A, Daniellou F, Garballeda G, et al. Activity analysis in participatory design and analysis of participatory design activity. International Journal of Industrial Ergonomics. 1995; 15: 311-327.

15. Douillet $P$, Schweitzer JM. TMS, stress: gagner des marges de manœuvre [Stress: increasing margins for manoeuvre]. BTS, Le stress au travail. 2002;(19-20):64-66.

16. Roquelaure Y, Malchaire J, Cock N, et al. Quantification de l'activité gestuelle au cours des tâches répétitives de production de masse [Quantifying gestural activity during repetitive mass production tasks]. Documents pour le médecin du_travail: DMT. 2001; 85:167-176.

17. Brunet M, Riff J. Analyse et exploitation de la variabilité gestuelle dans la prevention des TMS [Analysis and use of gestural variability in preventing MSDs]. Pistes. 2009; 11(1).

18. Coutarel F, Daniellou F, Dugué B. Interroger l'organisation du travail au regard des marges de manœuvre en conception et en fonctionnement. La rotation est-t-elle une solution aux TMS? [Questioning work organization in relation to margins for manoeuvre in design and operation. Is task rotation a solution to MSD?] Pistes. 2003; 5(2).

19. Béguin $P$, Cerf $M$. Formes et enjeux de l'analyse de l'activité pour la conception des systèmes de travail [Forms and challenges of activity analysis for designing work systems]. Activité. 2004; 1(1): 54-71.

20. Lamonde F, Richard JG, Langlois L, et al. La prise en compte des situations de travail dans les projets de conception [Consideration of work situations in design projects] (rapport R-636). Montréal: Institut de recherche Robert-Sauvé en santé et en sécurité du travail (IRSST); 2010.

21. Morais A, Aubineau A. Articulation entre l'ergonomie et le lean manufacturing chez PSA [Interplay between ergonomics and lean manufacturing at PSA]. Activités. 2012; 9(2): 179-197.

22. Bourgeois F. Gonon O. Le lean et l'activité humaine. Quel positionnement de l'ergonomie, convoquée par cette nouvelle doctrine de l'efficacité? [Lean manufacturing and human activity: what position for ergonomics under this new doctrine of efficiency?] Activités. 2010; 7(1): 136-142.

23. Falk A., Rosenkvist M. What are obstacles and needs of proactive ergonomics measures at early product development stages? - An interview study in five Swedish companies. International Journal of Industrial Ergonomics. 2012; 42: 406-415.

24. US Department of Defense. Military standard. Procedures for performing a failure mode, effects and criticality analysis (Mil-Std-1629A). Washington, DC: Department of Defense; 1980.

25. Neagoe BS. Recent researches in manufacturing engineering. 3rd WSEAS international conference on manufacturing engineering, quality and production systems (MEQAPS'11), Transilvania University of Brasov, Romania, 2011. 
26. FMEA info centre. Retrieved January 6, 2014, from: http://fmeainfocentre.com.

27. Liu H-C, Liu L, Liu N. Risk evaluation approach in failure mode and effects analysis: a literature review. Expert Systems with Applications. 2013; 40: 828-838.

28. Rhee S-J, Ishii K. Using cost based FMEA to enhance reliability and serviceability. Advance Engineering Informatics. 2003; 17: 179-188.

29. Subburaman K. A modified FMEA approach to enhance reliability of lean systems [master's thesis]. Knoxville (TN): University of Tennessee; 2010.

30. Barsky I, Dutta SP. Cost assessment for ergonomic risk (CAFER). International Journal of Industrial Ergonomics. 1997; 20: 307-315.

31. Village J, Annett T, Lin E, et al. Adapting the failure modes effect analysis (FMEA) for early detection of human factors concerns. Proceedings of the $42 \mathrm{nd}$ annual conference, Association of Canadian Ergonomists, October 18-20, 2011

32. Berthe F, Vimeux J. AMDEC Sécurité, 56è fiche, Favi. 1997. Retrieved January 6, 2014, from: http://www.favi.com/wp-content/uploads/2015/10/Fiche-56. pdf.

33. European Committee for Standardization (CEN). Safety of machinery - general principles for design - risk assessment and risk reduction (Standard No. EN ISO 12100: 2010). Brussels: CEN; 2010.

34. Lux A, Quillerou-Grivot E. Production activity analyzed by an engineer and a psychologist: what contributions for taking health into account when designing production systems ? Proceedings of the 10th International Conference on Modeling, Optimization et Simulation (MOSIM); 2014 Nov 5 -7; Nancy, France.

35. Rasmussen J. Risk Management in a dynamic society: a modeling problem. Safety Science. 1997; 27 (2-3): 183-213.

36. Polet $P$, Vanderhaegen F, Wieringa PA. Theory of safety-related violations of system barriers. Cognition Technology \& Work. 2002; 4: 171-179.

37. Vanderhaegen $F$, Zieba $S$, Enjalbert $S$, et al. A benefit/cost/deficit (BCD) model for learning from human errors. Reliability Engineering and System Safety. 2011; 96: 757766.

38. Bourgeois F. Que fait l'ergonomie que le lean ne sait/ne veut pas voir ? [What does ergonomics do that lean manufacturing cannot/will not see?] Activités. 2012; 9(2): 138147.

39. Hollnagel E. Accidents and barriers. Proceedings of the 7th European conference on cognitive science approaches to process control (CSAPC). 1999, Villeneuve d'Ascq, France: 175-180.

40. Genaidy A, Salem S, Karwowski W, et al. The work compatibility improvement framework: an integrated perspective of the human-at-work system. Ergonomics. 2007; 50(1): 3-25. 


\section{TABLES}

Table I. Example of an empty Process FMEA form

\begin{tabular}{|c|c|c|c|c|c|c|c|c|c|c|c|c|c|c|}
\hline $\begin{array}{l}\text { PROCESS } \\
\text { STEP }\end{array}$ & $\begin{array}{l}\text { FAILURE } \\
\text { MODE }\end{array}$ & EFFECT & 司 & CAUSE & 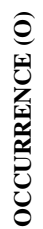 & DETECTION & 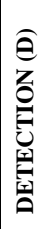 & $\begin{array}{l}0 \\
x \\
0 \\
x \\
x \\
\text { II } \\
z \\
z \\
x\end{array}$ & ACTIONS & $\begin{array}{l}\text { RESPON- } \\
\text { SIBILITY }\end{array}$ & DEADLINE & 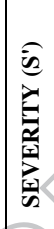 & 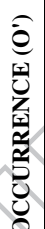 & 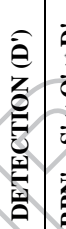 \\
\hline \multicolumn{15}{|c|}{ Workstation 000: Operation 000} \\
\hline
\end{tabular}

Note: RPN = Risk Priority Number

Table II. Example of work situation analysis using proposed table (from [38])

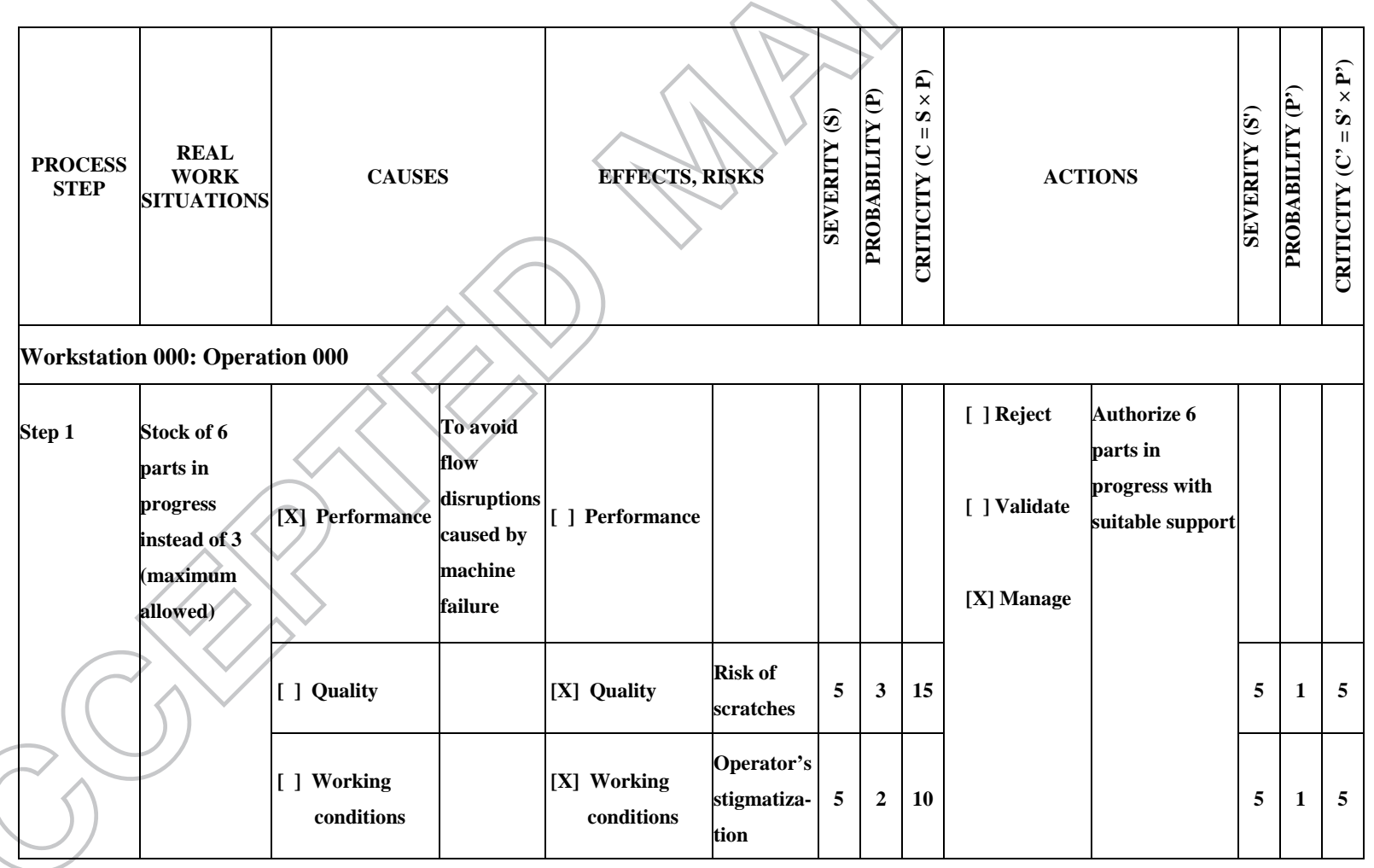

Note: Bolded figures are calculated: criticity (C) corresponds to the multiplication of severity (S) and probability $(\mathrm{P})$.

Table III. Example of failure analysis in a Process FMEA (from industrial case study) 


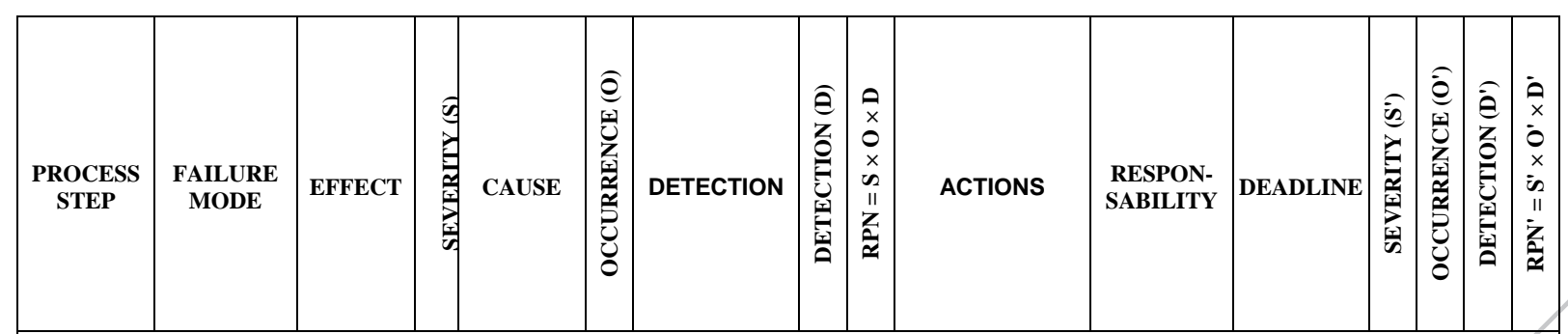

Workstation 010: WIRING HARNESS ASSEMBLY

\begin{tabular}{|l|c|c|c|c|c|c|c|c|c|c|c|c|}
\hline Clip fitting & No clip & $\begin{array}{c}\text { Noisy } \\
\text { product }\end{array}$ & 5 & $\begin{array}{c}\text { Operator } \\
\text { oversight }\end{array}$ & 3 & $\begin{array}{c}\text { Visual self- } \\
\text { inspection }\end{array}$ & 5 & 75 & $\begin{array}{c}\text { Clip pick-up } \\
\text { detection (hand } \\
\text { passing sensor) }\end{array}$ & AL & Feb. 14 & 5 \\
\hline
\end{tabular}

Note: Bolded figures are calculated: Risk Priority Number (RPN) corresponds to the multiplication of severity (S), occurrence (O) and detection (D). 
Table IV. Example of work situation analysis using proposed table (from industrial case study)

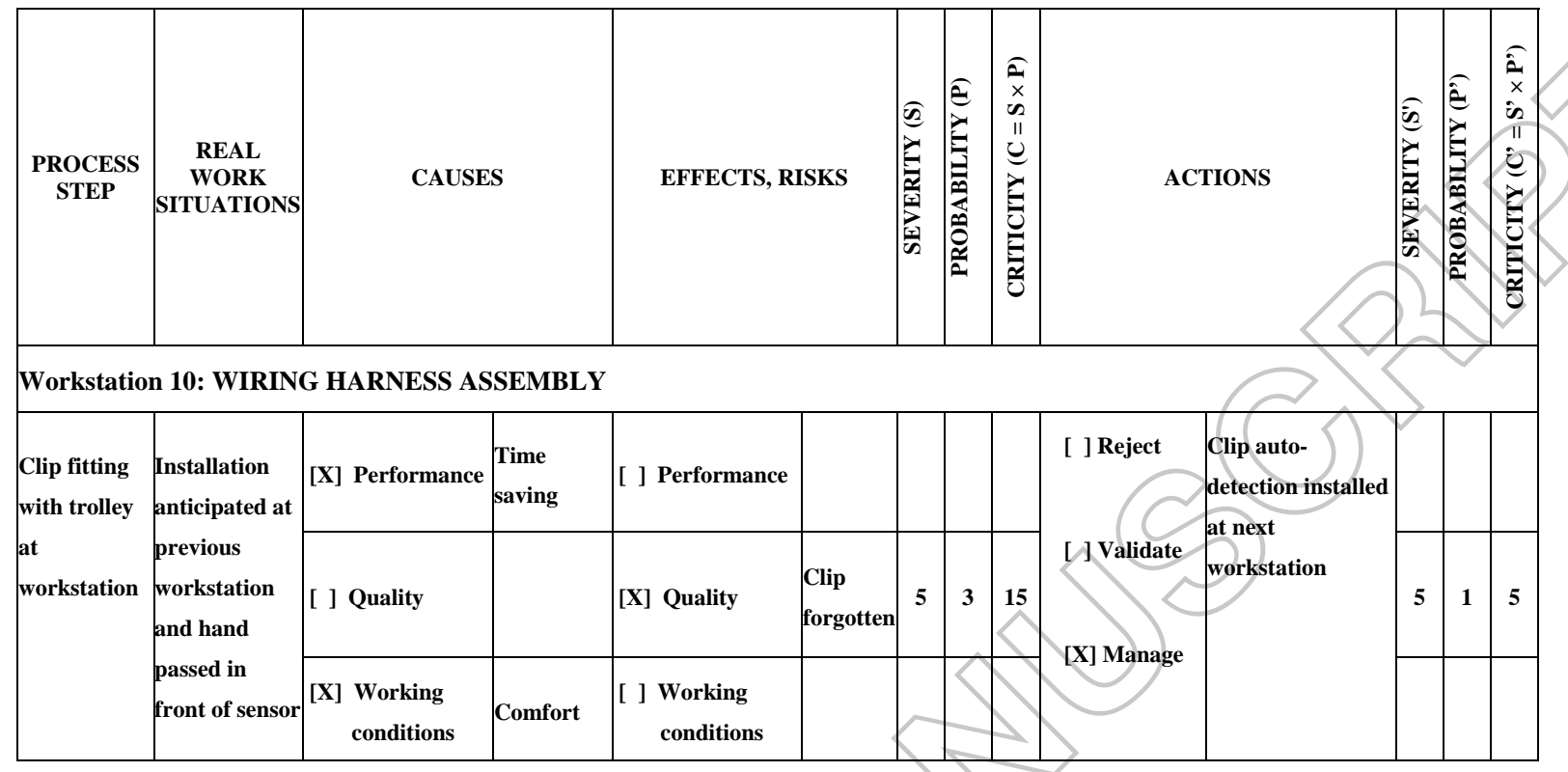

Note: Bolded figures are calculated: criticity (C) corresponds to the multiplication of severity (S) and probability (P). 